\title{
Transatlantica
}

Revue d'études américaines. American Studies Journal

Hors-série | 2021

Numéro anniversaire : 20 ans de la revue

\section{Carte blanche}

Jean Kempf

\section{(2) OpenEdition}

Journals

Édition électronique

URL : https://journals.openedition.org/transatlantica/17514

DOI : 10.4000/transatlantica. 17514

ISSN : 1765-2766

Éditeur

Association française d'Etudes Américaines (AFEA)

Référence électronique

Jean Kempf, « Carte blanche », Transatlantica [En ligne], Hors-série | 2021, mis en ligne le 04 octobre 2021, consulté le 11 octobre 2021. URL : http://journals.openedition.org/transatlantica/17514 ; DOI : https://doi.org/10.4000/transatlantica.17514

Ce document a été généré automatiquement le 11 octobre 2021.

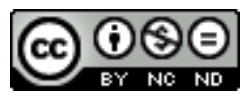

Transatlantica - Revue d'études américaines est mise à disposition selon les termes de la licence Creative Commons Attribution - Pas d'Utilisation Commerciale - Pas de Modification 4.0 International. 


\title{
Carte blanche
}

\author{
Jean Kempf
}

1 Transatlantica est née de quelques idées un peu vagues, dans un moment magmatique et primitif où l'on se disait qu'il était possible d'avoir un dialogue scientifique fructueux en dehors des formes canoniques (Howard Becker), que le support numérique ouvrait une avenue à celles et ceux, de plus en plus nombreux, qui travaillaient sur le non textuel, que l'on pouvait être à la fois agile et sérieux (pour l'hyper-contemporain entre autres), et, peut-être plus fondamentalement, que nos productions scientifiques n'étaient que des étapes dans un processus, que seul ne comptait pas l'article ou le livre finalisé (la fameuse pyramide de Darnton, mais aussi Le Débat).

On le voit, toutes ces promesses entrevues ou espérées ne se sont pas (encore) réalisées, certaines ont même attendu le COVID pour éclore (même si on en rêvait depuis longtemps), d'autres ont fait long feu (pour toutes sortes de raison), d'autres enfin, marges d'un moment, sont devenues la norme aujourd'hui, selon un procédé à la fois classique et imprévisible.

Alors, disons que la seule vertu des anniversaires est de rappeler que l'on a tenu tout ce temps. Et pour avoir tenu tout ce temps, il en a fallu du travail de toutes les équipes qui se sont succédé aux commandes: rédactrices et rédacteurs-en-chef, membres des comités de lecture, évaluateurs et évaluatrices, relecteurs et relectrices, secrétaires d'édition, etc. Il en a fallu aussi de l'imagination pour réinventer, au fil des années, un projet dont nous (l'AFEA) pouvons être fiers car non seulement il nous a donné de belles choses à lire, mais encore il a devancé beaucoup d'autres sociétés savantes dans les nouvelles pratiques de "la revue scientifique». Aujourd'hui la forme et la revue font l'unanimité, mais nous savons que ce ne fut pas toujours le cas. Il n'en est que plus important de rappeler le soutien des présidents, présidentes et bureaux successifs, depuis l'origine, car rien ne se serait fait sans lui. Continuons donc à innover dans le même esprit d'amitié scientifique, de risque aussi. Car Transatlantica et l'AFEA, c'est (pour moi) avant tout une histoire d'amitié, d'écoute, d'exigence. Ne devenons jamais des classiques. 


\section{AUTEUR}

JEAN KEMPF

Université Lumière Lyon 2, TRIANGLE 